\title{
High CCR7 mRNA expression of cancer cells is associated with lymph node involvement in patients with esophageal squamous cell carcinoma
}

\author{
KOICHIRO ISHIDA ${ }^{1}$, MAKOTO IWAHASHI ${ }^{1}$, MIKIHITO NAKAMORI ${ }^{1}$, MASAKI NAKAMURA ${ }^{1}$, \\ SHOZO YOKOYAMA $^{1}$, TAKESHI IIDA ${ }^{1}$, TEIJI NAKA ${ }^{1}$, YASUSHI NAKAMURA ${ }^{2}$ and HIROKI YAMAUE ${ }^{1}$ \\ ${ }^{1}$ Second Department of Surgery and ${ }^{2}$ Division of Pathology, Department of Clinical Laboratory Medicine, \\ Wakayama Medical University, School of Medicine, Wakayama, Japan
}

Received November 26, 2008; Accepted January 22, 2009

DOI: 10.3892/ijo_00000217

\begin{abstract}
Esophageal squamous cell carcinoma (SCC) is one of the biological malignant tumors. Once a tumor invades the submucosa, an incidence of lymph node (LN) metastases is very high, thus resulting in poor survival. Recently, chemokines have been reported to play an important role in organspecific metastases in several malignancies. In particular, CCR7 has been reported to be associated with LN metastases by immunohistochemistry. However, there have been no studies of quantitative analyses of CCR7 mRNA expression on cancer cells. In this study, we investigated the clinical significance of the expression of CCR7 in the establishment of LN metastases of esophageal SCC. A series of 78 patients with esophageal SCC who underwent esophagectomy were consecutively selected. The expression of CCR7 mRNA from tumor tissue samples was analyzed by quantitative real-time reverse transcriptase-polymerase chain reaction (qRT-PCR), and that from cancer cell samples collected using laser microdissection system was analyzed by qRT-PCR. Immunohistochemical staining of CCR7 was also performed. Although CCR7 mRNA expression in tumor tissues demonstrated no association with the LN metastases, that in cancer cells correlated with $\mathrm{LN}$ metastases $(\mathrm{p}<0.05)$ due to the fact that not only cancer cells but also infiltrating lymphocytes expressed CCR7 in tumor tissue. Multivariate logistic regression analysis revealed a high CCR7 expression in cancer cells to be an independent predictive factor for $\mathrm{LN}$ metastases. These results suggested that CCR7 expression might play an important role in establishing LN metastases in patients with esophageal SCC.
\end{abstract}

Correspondence to: Dr Makoto Iwahashi, Second Department of Surgery, Wakayama Medical University, School of Medicine, 811-1, Kimiidera, Wakayama 641-8510, Japan

E-mail: makoto@wakayama-med.ac.jp

Key words: esophageal squamous cell carcinoma, lymph node metastases, CCR7, quantitative real-time RT-PCR

\section{Introduction}

Esophageal squamous cell carcinomas (SCCs) are malignant, once the tumors invade the sub-mucosa, $8.3-28.6 \%$ have lymph node involvements and in $234.8-54.1 \%$ deeper invasion to submucosa causes lymph node metastases, resulting in poor survival (1-6).

Chemokines have previously been reported to play an important role in both tumor growth and in establishing organ-specific metastases in several malignancies (7-19). The expression of CXCR4 in gastric cancer correlates with peritoneal dissemination (9) and cancerous CXCL12 expression was an independent prognostic factor in gastric cancer (10) and the expression of CCR6 in colorectal cancer is associated with synchronous liver metastases (11). CCR7 is concerned with the homing of lymphocytes to secondary lymphoid organs. Müller et al have reported the expression of the ligands of chemokines in the organs to be associated with the formation of metastases and the CCR7/CCL21 axis has also been shown to play an important role in lymph node metastases in breast cancer (12). Since then, several studies have also reported the CCR7 expression to be associated with lymph node metastases in malignant melanoma $(13,14)$, breast carcinoma (15), non-small cell lung carcinoma (16) and gastrointestinal carcinomas (17). In gastric cancer, the CCR7 expression has a significant correlation with lymph node metastasis and lymphatic invasion by immunohistochemical analysis (18). In esophageal SCC, a high expression of CCR7 is associated with lymph node metastasis, TNM-stage and depth of tumors, resulting in poor survival in immunohistochemical study (19).

However, there have been no studies of quantitative analyses of CCR7 mRNA expression on cancer cells. Whole tumor tissue contains not only cancer cells but also many infiltrating lymphocytes which express CCR7. Therefore, it is important to exclude infiltrating lymphocytes when we quantitatively analyze CCR7 expression in tumor tissue.

In this study, we quantitatively investigated the expression of CCR7 mRNA in cancer cells using laser microdissection in patients with esophageal SCC, and we assessed the association of CCR7 expression with lymph node metastases to clarify the role of the CCR7 in cancer 
cells in the establishment of lymph node metastases in patients with esophageal SCC.

\section{Materials and methods}

Patient selection and tissue specimens. A series of 78 patients with esophageal SCC who underwent esophagectomies at Wakayama Medical University Hospital between April 2003 and February 2006 were consecutively selected. Most of the patients had undergone an esophagectomy with lymph node dissection through a right thoracotomy. None of them received either chemotherapy or radiotherapy before surgery. Clinicopathological characteristics of these 78 patients are shown in Table I. The tumor specimens were divided into two parts. One was immediately frozen in liquid nitrogen after surgical resection and stored at $-80^{\circ} \mathrm{C}$ until RNA extraction, and the other was fixed in a $10 \%$ formaldehyde solution and embedded in paraffin for immunohistochemical analysis and for common histological diagnosis. The primary tumors of the esophagus were histologically examined with hematoxylin and eosin staining according to TNM classification of malignant tumors by UICC (20).

Forty-three tissue samples, out of 78 patients, were large enough for sampling by laser microdissection (LMD) and were analyzed for quantitative real-time RT-PCR. In addition, the 78 tissue samples were analyzed immunohistochemically.

Written informed consent was obtained from all patients before their participation in this study. In addition, the local Ethics Committee of Wakayama Medical University approved this study.

Laser microdissection. For LMD, each tissue block was cut off from 43 specimens and embedded in the Tissue Tek OCT medium (Sakura, Tokyo, Japan) and frozen in liquid nitrogen for $30 \mathrm{~min}$. The frozen tissue blocks were sliced in 6-8 $\mu \mathrm{m}$ by Cryostat (Sakura) and mounted on foil-coated glass slide (FOIL-SL25; Leica Microsystems). Before LMD, the sections were fixed with $70 \%$ ethanol for $1 \mathrm{~min}$ at $-20^{\circ} \mathrm{C}$ and after washing in ethanol, they were stained with hematoxylin for $1 \mathrm{~min}$. After being air dried, the cancer cells of the sections were selectively microdissected using the Leica LMD System (Leica Microsystems, Welzlar, Germany) (21-23).

RNA extraction and complementary DNA synthesis. Total RNA was extracted from tumor tissue specimens using RNeasy mini kit (Qiagen, Hilden, Germany) and as well as from microdissected cancer cells using RNeasy micro kit (Qiagen). The quality of RNA was assessed by 2100 Bioanalyzer (Agilent Technologies, Palo Alto, CA) for quantitative RT-PCR.

Complementary DNA (cDNA) was generated with the transcriptor first-strand cDNA synthesis kit (Roche Diagnostics, Mannheim, Germany). The total RNA $(1 \mu \mathrm{g})$ was denaturated in a $13 \mu 1$ solution for $10 \mathrm{~min}$ at $65^{\circ} \mathrm{C}$. The cDNA synthesis reaction was performed at $55^{\circ} \mathrm{C}$ for $30 \mathrm{~min}$ and heated at $85^{\circ} \mathrm{C}$ for 5 min for inactivation.

Quantitative real-time RT-PCR. Quantitative real-time RTPCR (quantitative RT-PCR) was performed with the isolated total RNA ( $1 \mu \mathrm{g})$ on LightCycler system (Roche, Germany).
Table I. Clinicopathological data of the patient population.

Gender

Female/male

Age

Depth of tumor

T1/T2/T3/T4

Differentiation

Wel/Mod/Por/x

$19 / 36 / 19 / 4$

Tumor localization

Proximal 1/3/middle 1/3/distal 1/3

$12 / 34 / 32$

Lymphatic invasion

ly(-)/ly(+)/lyx

Vascular invasion

$\mathrm{v}(-) / \mathrm{v}(+) / \mathrm{vx}$

$34 / 38 / 6$

Status of lymph node metastasis ${ }^{a}$

N0/N1/M1a/M1b

$38 / 16 / 13 / 11$

TNM stage

0/I/IIA/IIB/III/IVA/IVB

$0 / 16 / 20 / 7 / 10 / 13 / 12$

According to the TNM classification, we clarified 78 patients. Wel, well differentiated; Mod, moderately differentiated; Por, poorly differentiated; The $\mathrm{x}$ is that differentiation of tumor cannot be assessed because those tumors invaded until slight submucosa. ${ }^{\text {aStatus }}$ of lymph node metastasis shows both regional lymph node metastasis and distant lymph node metastasis.

The following oligonucleotide primers and hybridization probes were used: human CCR7 (Gene Bank accession no. NM_001838; 969-1199 bp) sense (5'-GCAACTCAACATCG CCTACG-3') and antisense (5'-TATGGGGAGAAGGT GGTGGT-3'), Fluorescein-labeled probe (5'-ACCCTTTCTT GTACGCCTTCATCGG-3'), and LC Red 640-labeled probe (5'-GTCAAGTTCCGCAACGATCTCTTCAAG-3'), human GAPDH (Gene Bank accession no. NM_002046; 746-1052 bp) sense (5'-TGAACGGGAAGCTCACTGG-3') and antisense (5'-TCCACCACCCTGTTGCTGTA-3'), Fluorescencelabeled probe (5'-TCAACAGCGACACCCACTCCT-3') and LC Red 640-labeled probe (5'-CACCTTTGACGCTGGG GCT-3'). All primers and probes were designed and synthesized at the Nihon Gene Research Laboratory, Inc.

CCR7 cDNA was amplified by 50 cycles of denaturation at $95^{\circ} \mathrm{C}(10 \mathrm{sec})$, annealing at $60^{\circ} \mathrm{C}(10 \mathrm{sec})$ and extension at $72^{\circ} \mathrm{C}(12 \mathrm{sec})$. GAPDH cDNA was amplified by 55 cycles of denaturation at $95^{\circ} \mathrm{C}(10 \mathrm{sec})$, annealing at $55^{\circ} \mathrm{C}(15 \mathrm{sec})$ and extension at $72^{\circ} \mathrm{C}(9 \mathrm{sec})$.

On each run, we quantified all samples according to the LightCycler software program ver. 3.8. The values of CCR7 were standardized by the values of GAPDH in all samples.

Since it was assumed that the CCR7 expression demonstrated a logarithmic normal distribution, we used the following for quantitative RT-PCR analysis: CCR7 ratio $=\log$ (CCR7 value/GAPDH value * $10^{4}$ ).

Immunohistochemistry. Immunohistochemical staining was performed by the polymer envision method. For the double 
A
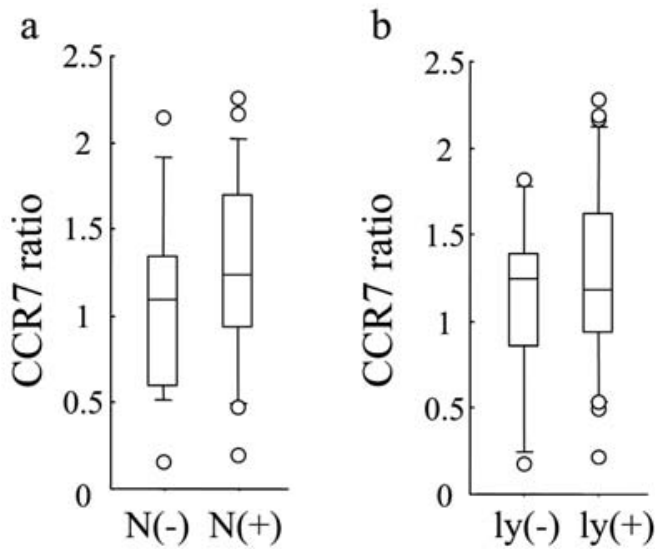

B
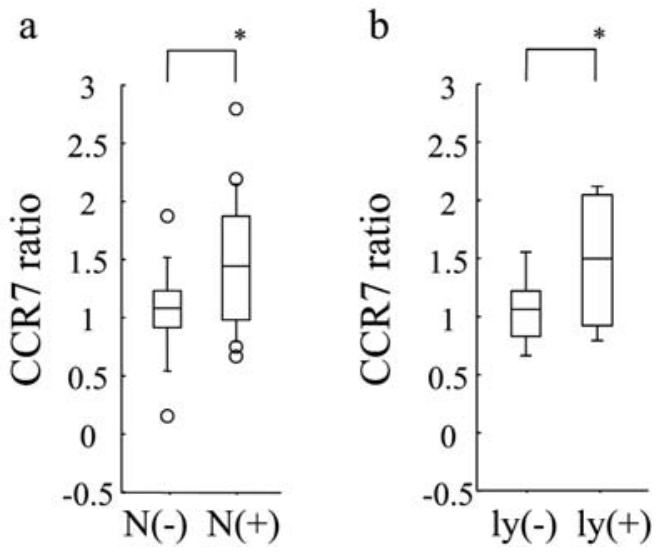

C

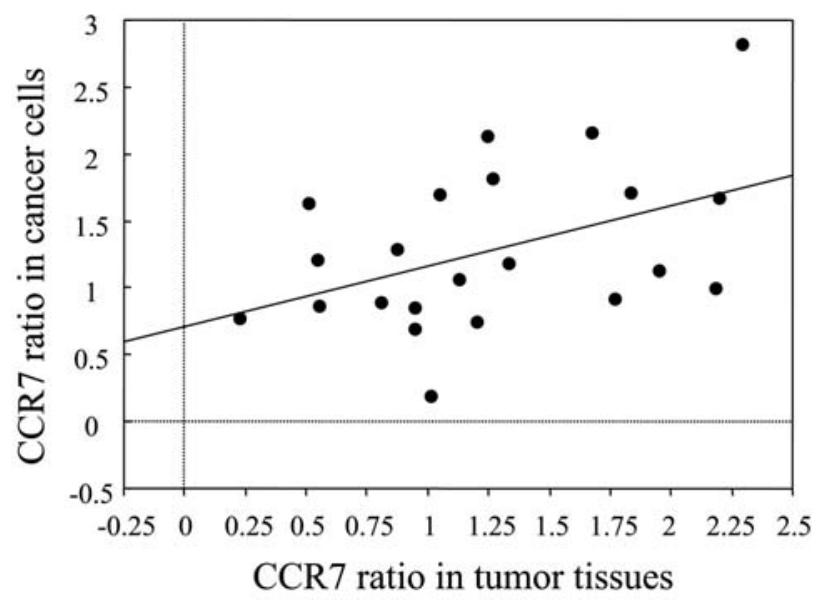

Figure 1. (A) Correlation between the expression of CCR7 mRNA in tumor tissue specimens and the presence of either lymph node metastases or lymphatic invasion. $(A, a) N(+)(n=15) / N(-)(n=19)$ is the group of the patients with/without the lymph node metastasis. $(A, b) \operatorname{ly}(+)(n=5) / 1 y(-)(n=28)$ is defined as the tumor tissue with/without lymphatic invasion. (B) Correlation between the expression of CCR7 mRNA in the cancer cells themselves and the presence of either lymph node metastases or lymphatic invasion. $(\mathrm{B}, \mathrm{a})$ $\mathrm{N}(+)(\mathrm{n}=12) / \mathrm{N}(-)(\mathrm{n}=21)$ is the group of the patients with/without the lymph node metastasis. $(\mathrm{B}, \mathrm{b}) \mathrm{ly}(+)(\mathrm{n}=15) / \mathrm{ly}(-)(\mathrm{n}=18)$ is defined as tumor tissue with/without lymphatic invasion. ${ }^{*} \mathrm{P}<0.05$. (C) Correlation between the CCR7 mRNA expression in tumor tissues and that in cancer cells $(n=22)$. staining method, two antibodies were used: anti-h CCR7 (Epitomics, Inc, CA, USA) and anti-h Leucocyte Common Antigen (LCA) (DakoCytomation, Denmark). The 5- $\mu \mathrm{m}$ tissue sections were heated at $121^{\circ} \mathrm{C}$ in an autoclave for $7 \mathrm{~min}$ after deparaffinization and rehydration. Endogenous peroxidase activity was suppressed by a solution of $0.3 \%$ hydrogen peroxide in methanol for $5 \mathrm{~min}$. After being rinsed in Tris-TBS, the sections were incubated with a blocking reagent: Protein block (Dako, Kyoto, Japan) for $20 \mathrm{~min}$ at room temperature. The sections were incubated overnight at $4^{\circ} \mathrm{C}$ with the 1 st antibody. After rinsing, the sections were incubated for 90 min with the 2nd antibody: Histofine Simple Stain (Nichirei, Tokyo, Japan). Color reaction was developed in AEC solution (DakoCytomation). After the 1st reaction was inactivated with $0.1 \mathrm{M}$ glycine buffer ( $\mathrm{pH} 2.2$ ), the sections were then incubated overnight at $4^{\circ} \mathrm{C}$ with next 1 st antibody. After rinsing, they were incubated for 60 min with the 2nd antibody: namely, anti-mouse or rabbit Ig/AP (Dako Cytomation) and then after rinsing, they were reacted with Vector Blue (Vector Laboratories, Inc, USA).

The primary cancer tissue specimens were double stained with CCR7 and LCA and the sections were regarded as CCR7positive when the intensity of staining was $>10 \%$.

Statistical analysis. Comparisons between the CCR7 ratio and the clinicopathological features were performed using either Student's t-test or ANOVA as appropriate. The diagnostic accuracy of CCR7 expression with regard to the presence of lymph node metastases was quantified via a receiver operating characteristic (ROC) analysis $(24,25)$. The associations between CCR7 expression and clinicopathological features were evaluated by either the $\chi^{2}$ test or Fisher's exact test as appropriate. Univariate and multivariate logistic regression analyses were carried out to investigate whether the presence of CCR7 expression would be an independent risk factor for lymph node metastases. All analyses were performed using the Stat View-J ver.5.0 software program and all tests were two-sided with a significance level of $\mathrm{p}<0.05$.

\section{Results}

Correlation between CCR7 mRNA expression in tumor tissues and lymph node metastases or lymphatic invasion. We first examined the mRNA expression of CCR7 in whole tumor tissue specimens. The expression of CCR7 mRNA in tumor tissue specimens was not significantly associated with either lymph node involvement or with lymphatic invasion (Fig. 1A).

Immunohistochemistry for CCR7 in tumor tissues. Immunohistochemistry for CCR7 was performed to examine where CCR7 was expressed in the tumor tissue specimens. CCR7 was expressed in the cytoplasm and cell membrane of cancer cells (Fig. 2A-C). In most samples, CCR7 was expressed heterogeneously (Fig. 2C). On the other hand, CCR7 was constantly expressed in normal lymphocytes. Expression level of CCR7 was usually higher in normal lymphocytes than in cancer cells (Fig. 2A-E). Therefore, the expression of CCR7 mRNA in tumor tissues was derived from both cancer cells and infiltrating lymphocytes. 

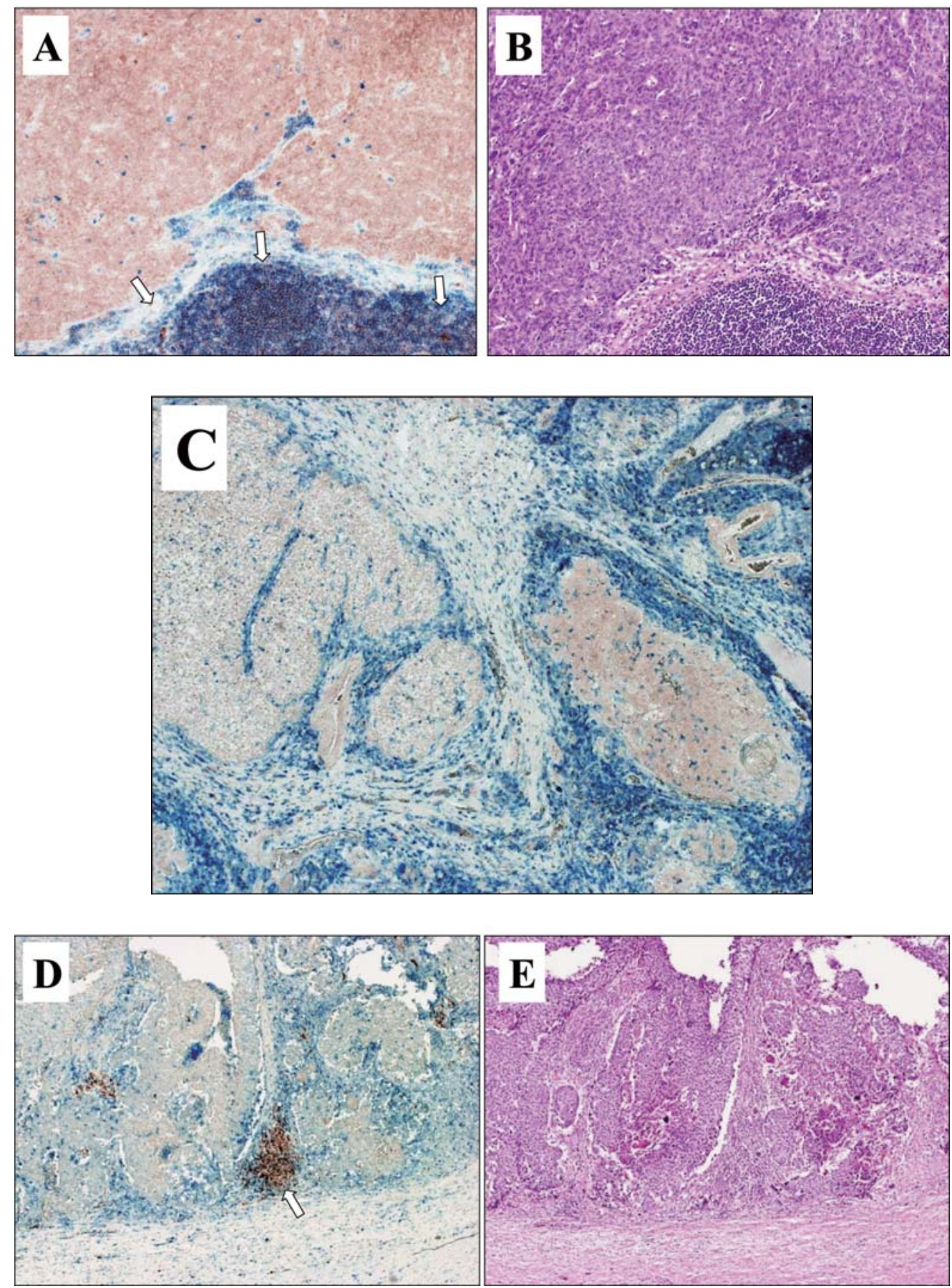

Figure 2. CCR7 expression in representative esophageal SCC specimens was assessed by immunohistochemistry. Original magnification, $\mathrm{x} 40$. (A) Both CCR7 and LCA were stained in the tumor tissue specimens (outline arrows show lymphocytes). (B) H\&E staining of the specimens, which is similar to A. (C) CCR7 was expressed heterogeneously in the tumor tissue specimens. (D) Both CCR7 and LCA were stained in lymphocytes (outline arrows). (E) H\&E staining of the specimen, which is similar to $\mathrm{D}$.

Correlation between CCR7 mRNA expression in cancer cells themselves and lymph node metastases. To investigate the expression of CCR 7 mRNA in the cancer cells, we selectively microdissected cancer cells using the LMD system and extracted total RNA from cancer cells in 43 tumor tissues (Fig. 3). We analyzed the quality of the extracted RNA by using 2100 Bioanalyzer, the extracted RNA in 10 of 43 cases was found to be damaged and therefore it was excluded from the subsequent RT-PCR. The expression of CCR7 mRNA in cancer cells in cases with lymph node metastasis was higher than that in cases without lymph node metastasis $(\mathrm{p}<0.05)$.
Other clinicopathological factors were also compared between the cases with lymph node metastases and without lymph node metastases. A significant difference in the expression of CCR7 mRNA was observed in the presence of lymphatic invasion $(\mathrm{p}<0.05)$ (Fig. 1B), but no such difference was seen in either the presence of vessel invasion or in any other factors (data not shown).

Twenty-two of the 33 cases were assessed for the level of CCR7 mRNA both in tumor tissue specimens and cancer cells. As expected, these groups had a low correlation $(\mathrm{R}=0.443$, p $<0.05$ ) (Fig. 1C). 


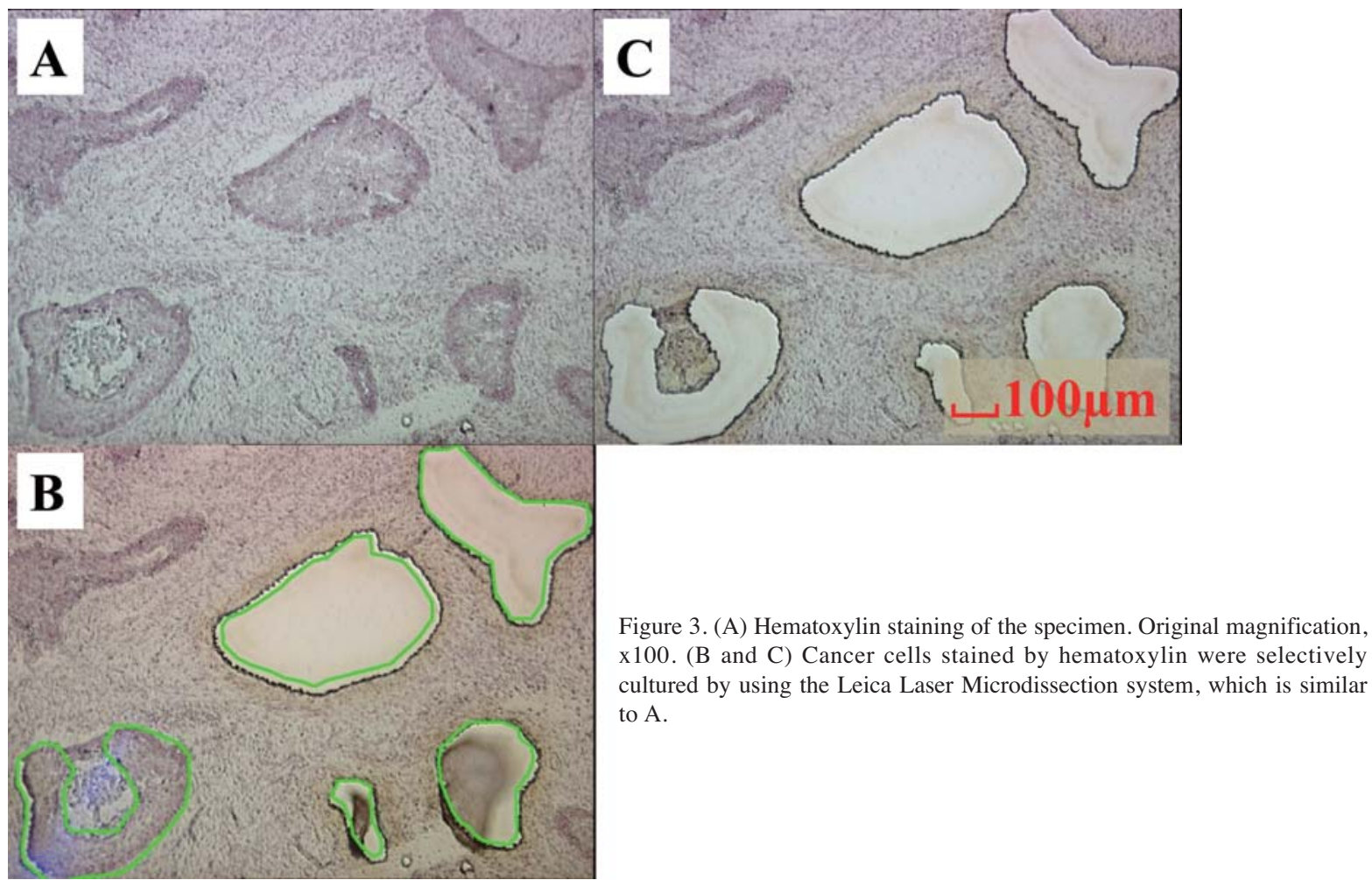

Table II. Comparison of the clinicopathological characteristics with the CCR7 expression.

\begin{tabular}{|c|c|c|c|}
\hline \multirow[b]{2}{*}{ Clinical factor } & \multicolumn{2}{|c|}{ CCR7 expression } & \multirow{2}{*}{$\begin{array}{c}\begin{array}{c}\text { Comparison of } \\
\text { high vs. low group }\end{array} \\
\text { P }\end{array}$} \\
\hline & Low $(n=18)$ & High $(n=15)$ & \\
\hline \multicolumn{4}{|l|}{ Gender } \\
\hline Female/Male & $2 / 16$ & $4 / 11$ & $0.2487^{\mathrm{a}}$ \\
\hline \multicolumn{4}{|l|}{ Age } \\
\hline$<65$ years $/>65$ years & $7 / 11$ & $8 / 7$ & $0.4067^{\mathrm{a}}$ \\
\hline \multicolumn{4}{|l|}{ Depth of tumor } \\
\hline $\mathrm{T} 1, \mathrm{~T} 2 / \mathrm{T} 3, \mathrm{~T} 4$ & $1 / 17$ & $3 / 12$ & $0.2055^{\mathrm{a}}$ \\
\hline \multicolumn{4}{|l|}{ Differentiation } \\
\hline Wel/Mod/Por & $5 / 10 / 3$ & $7 / 4 / 4$ & $0.2468^{\mathrm{b}}$ \\
\hline \multicolumn{4}{|l|}{ Lymphatic invasion } \\
\hline Negative/Positive & $11 / 7$ & $4 / 11$ & $0.0479^{\mathrm{a}, \mathrm{c}}$ \\
\hline \multicolumn{4}{|l|}{ Vascular invasion } \\
\hline Negative/Positive & $6 / 12$ & $7 / 8$ & $0.3144^{\mathrm{a}}$ \\
\hline \multicolumn{4}{|l|}{ Lymph node metastasis } \\
\hline Negative/Positive & $10 / 8$ & $2 / 13$ & $0.0121^{\mathrm{a}, \mathrm{c}}$ \\
\hline \multicolumn{4}{|c|}{ Number of the metastatic LNs } \\
\hline $0-3 / 4-7 / 8-$ & $14 / 1 / 3$ & $9 / 4 / 2$ & $0.2420^{\mathrm{b}}$ \\
\hline \multicolumn{4}{|l|}{ TNM N and M } \\
\hline N0/N1/M1a/M1b & $10 / 4 / 1 / 3$ & $2 / 5 / 5 / 3$ & $0.0480^{\mathrm{b}, \mathrm{c}}$ \\
\hline \multicolumn{4}{|l|}{ TNM stage } \\
\hline I, IIA/IIB, III/IVA, IVB & $10 / 4 / 4$ & $3 / 4 / 8$ & $0.0876^{\mathrm{b}}$ \\
\hline
\end{tabular}

Wel, well differentiated; Mod, moderately differentiated and Por, poorly differentiated. ${ }^{\mathrm{a}} \chi^{2}$ test; ${ }^{\mathrm{b}}$ Fisher's exact test and ${ }^{\mathrm{c}} \mathrm{P}<0.05$. 
Table III. Clinicopathological characteristics regarding presence of lymph node metastasis.

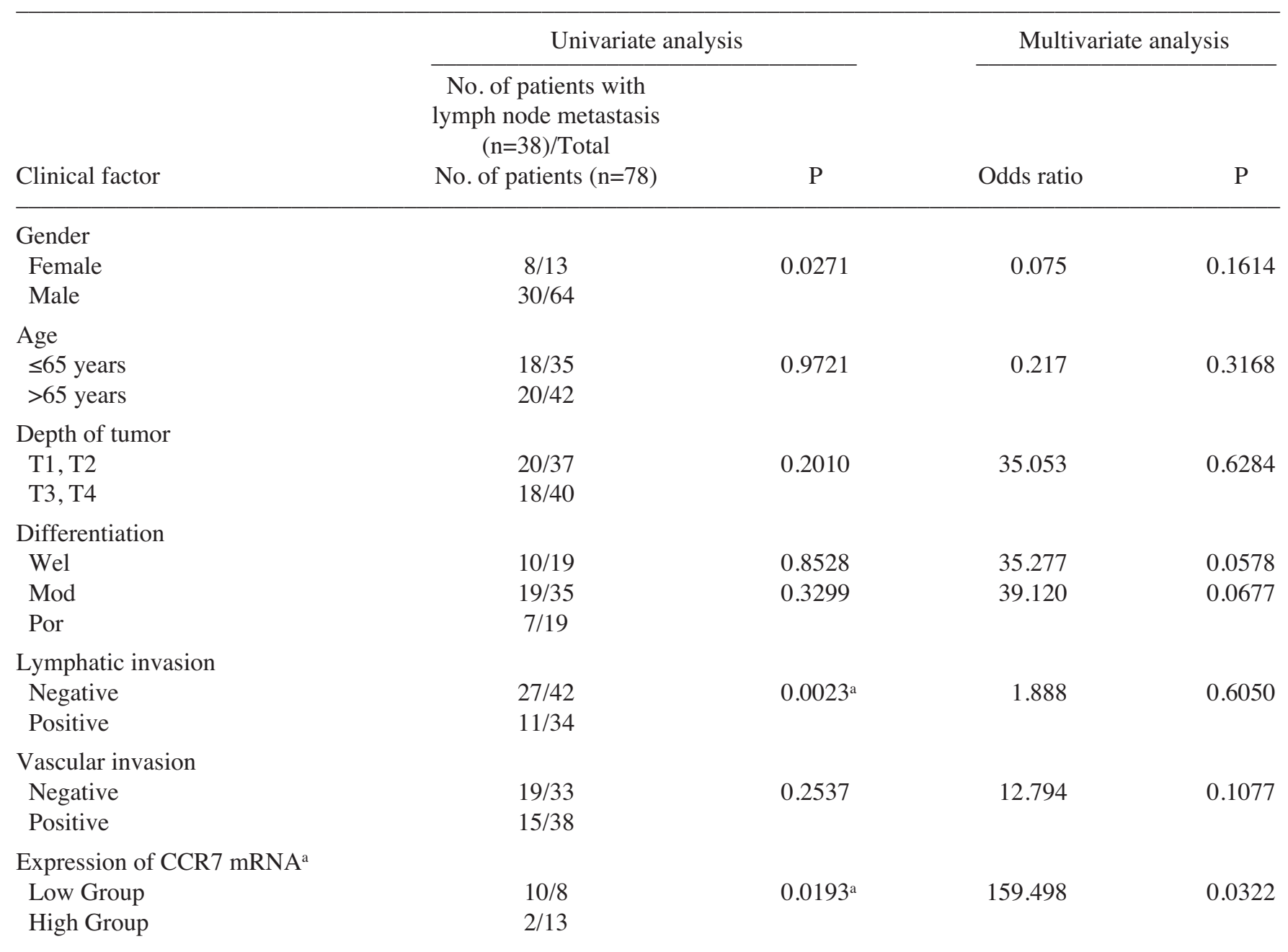

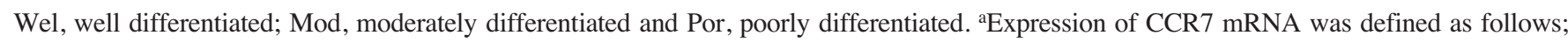
Cutoff determined by the ROC curve was 1.275 . We regarded patients with a higher CCR7 mRNA expression than the cutoff as belonging to the high group.

Comparison of clinicopathological characteristics with CCR7 expression of cancer cells. The optimal cutoff level of CCR7 mRNA expression for differentiation between positive and negative lymph node metastases was set at 1.275 by constructing a ROC curve. The sensitivity, the specificity and the accuracy of this cutoff line was $61.9,83.3$ and $69.7 \%$, respectively. Patients were dichotomized as having either a high or low CCR7 expression based on this cutoff level. In addition, the clinicopathological characteristics of the patients were assessed with respect to high vs. low CCR7 expression. Twenty-one of the 33 patients had lymph node metastases. The $\chi^{2}$ test or Fisher's exact test revealed an association between high vs. low CCR7 expression and the presence of lymph node metastases, lymphatic invasion of the tumors (Table II).

Correlation of CCR7 expression of cancer cells and the presence of lymph node metastases. The patients were grouped according to the presence of lymph node metastases and both univariate analysis and multivariate logistic regression analysis were carried out to identify any independent risk factors for lymph node metastases.
Thirty-eight of the 78 patients had lymph node metastasis. Univariate analyses revealed an association between a CCR7 mRNA high expression, as well as lymphatic invasion and lymph node metastasis $(\mathrm{p}<0.05)$.

A multivariate logistic regression analysis, with the presence of lymph node metastases as the dependent variable and all other clinicopathological parameters as independent variables, confirmed the presence of lymph node metastases only to be associated with the expression of CCR7 mRNA (odds ratio: 159.498, p<0.05) (Table III).

\section{Discussion}

CCR7 is a chemokine receptor, which is expressed on lymphocytes, such as T cells and dendritic cells and it plays an important role in the mediation of migration of those cells toward lymph nodes which express the CCR7 ligand, CCL21 (26).

CCR7 expression in tumor tissue specimens has recently been reported to be associated with lymph node metastases by immunohistochemical analyses in various carcinomas 
(12-19). However, there are no studies to investigate this correlation quantitatively, although the chemokinechemokine receptor interaction is targeted in terms of chemotaxics of cancer cells. In this study, we quantitatively examined CCR7 expression of cancer cells by evaluating the mRNA expression, because we thought that the quantity of a chemokine and its receptor were crucial for establishing chemotactic metastases. When we evaluated the mRNA expression level of CCR7 in tumor tissue specimens, the following critical issue remains: A large number of lymphocytes sometimes infiltrate into tumor tissues, suggesting that tumor tissue specimens contain not only cancer cells, but also tumor-infiltrating lymphocytes.

Moreover, our results showed that CCR7 mRNA expression in cancer cells was heterogeneous and extremely low in comparison to that in lymphocytes by immunohistochemisty, and, of course, no correlation was recognized between its expression in tumor tissues and that in cancer cells. Therefore, the evaluation of CCR7 mRNA of whole tumor tissue specimens may not be an accurate indicator for assessing lymph node metastases, and we selectively microdissected cancer cells by using the LMD system to elucidate the CCR7 mRNA expression level in cancer cells themselves in the present study. The results showed the CCR7 mRNA expression of cancer cells in patients with lymph node involvement to be significantly higher than that in patients without lymph node involvement.

Furthermore, when the patients were identified to have a high or low CCR7 expression in cancer cells based on the cutoff level set by constructing a ROC curve, a high CCR7 expression was found to be a significant independent risk factor for lymph node involvement based on a multivariate logistic regression analysis. These findings strongly suggested that CCR7 expressed in cancer cells might play a crucial role in the establishment of lymph node metastases.

CCL21, which is the ligand of CCR7, has been reported to be a key stimulator of cancer cells to migrate into the lymphatic systems $(27,28)$. Lymphatic endothelial cells (LEC) release CCL21, that stimulates malignant melanoma cells to cause directional migration in vitro and melanoma in vivo shows directional growth towards LEC, suggesting that cancer cells recognize and respond to signal given off by the LEC (29). Taken together, cancer cells expressing high level of CCR7 home in on the lymphatics by releasing CCL21 and migrate to lymph node, establishing lymph node metastases.

In conclusion, the high expression of CCR7 mRNA in the cancer cells was clearly associated with lymph node metastases and it was also considered to be an independent predictive factor for lymph node metastases. Therefore, the expression of CCR7 may play an important role in establishing lymph node metastases in patients with esophageal SCC.

\section{References}

1. Akiyama H, Tsurumaru M, Udagawa H and Kajiyama Y: Radical lymph node dissection for cancer of the thoracic esophagus. Ann Surg 220: 364-373, 1994.
2. Fujita H, Kakegawa T, Yamana H, et al: Mortality and morbidity rates, postoperative course, quality of life, and prognosis after extended radical lymphadenectomy for esophageal cancer. Comparison of three-field lymphadenectomy with two-field lymphadenectomy. Ann Surg 222: 654-662, 1995.

3. Altorki N, Kent M, Ferrara C and Port J: Three-field lymph node dissection for squamous cell and adenocarcinoma of the esophagus. Ann Surg 236: 177-183, 2002.

4. Lerut T, Nafteux P, Moons J, et al: Three-field lymphadenectomy for carcinoma of the esophagus and gastroesophageal junction in 174 R0 resections: impact on staging, disease-free survival, and outcome: a plea for adaptation of TNM classification in upperhalf esophageal carcinoma. Ann Surg 240: 962-974, 2004.

5. Fang WT, Chen WH, Chen Y and Jiang Y: Selective three-field lymphadenectomy for thoracic esophageal squamous carcinoma. Dis Esophagus 20: 206-211, 2007.

6. Tachibana M, Hirahara N, Kinugasa S and Yoshimura H: Clinicopathologic features of superficial esophageal cancer: results of consecutive 100 patients. Ann Surg Oncol 15: 104-116, 2008.

7. Kang H, Mansel RE and Jiang WG: Genetic manipulation of stromal cell-derived factor- 1 attests the pivotal role of the autocrine SDF-1-CXCR4 pathway in the aggressiveness of breast cancer cells. Int J Oncol 26: 1429-1434, 2005.

8. Ishikawa T, Nakashiro K, Hara S, et al: CXCR4 expression is associated with lymph node metastasis of oral squamous cell carcinoma. Int J Oncol 28: 61-66, 2006.

9. Yasumoto K, Koizumi K, Kawashima A, et al: Role of the CXCL12/CXCR4 axis in peritoneal carcinomatosis of gastric cancer. Cancer Res 66: 2181-2187, 2006.

10. Ishigami S, Natsugoe S, Okumura $\mathrm{H}$, et al: Clinical implication of CXCL12 expression in gastric cancer. Ann Surg Oncol 14: 3154-3158, 2007.

11. Ghadjar P, Coupland SE, Na IK, et al: Chemokine receptor CCR6 expression level and liver metastases in colorectal cancer. J Clin Oncol 24: 1910-1916, 2006.

12. Müller A, Homey B, Soto H, et al: Involvement of chemokine receptors in breast cancer metastasis. Nature 410: 50-56, 2001.

13. Wiley HE, Gonzalez EB, Maki W, Wu MT and Hwang ST: Expression of CC chemokine receptor-7 and regional lymph node metastasis of B16 murine melanoma. J Natl Cancer Inst 93: 1638-1643, 2001.

14. Takeuchi H, Fujimoto A, Tanaka M, Yamano T, Hsueh E and Hoon DS: CCL21 chemokine regulates chemokine receptor CCR7 bearing malignant melanoma cells. Clin Cancer Res 10: 2351-2358, 2004

15. Cabioglu N, Yazici MS, Arun B, et al: CCR7 and CXCR4 as novel biomarkers predicting axillary lymph node metastasis in T1 breast cancer. Clin Cancer Res 11: 5686-5693, 2005.

16. Takanami I: Overexpression of CCR7 mRNA in nonsmall cell lung cancer: correlation with lymph node metastasis. Int J Cancer 105: 186-189, 2003.

17. Günther K, Leier J, Henning G, et al: Prediction of lymph node metastasis in colorectal carcinoma by expression of chemokine receptor CCR7. Int J Cancer 116: 726-733, 2005.

18. Mashino K, Sadanaga N, Yamaguchi H, et al: Expression of chemokine receptor CCR7 is associated with lymph node metastasis of gastric carcinoma. Cancer Res 62: 2937-2941, 2002.

19. Ding Y, Shimada Y, Maeda M, et al: Association of CC chemokine receptor 7 with lymph node metastasis of esophageal squamous cell carcinoma. Clin Cancer Res 9: 3406-3412, 2003.

20. Sobin LH and Wittekind CH (eds): TNM Classification of Malignant Tumors. 5th edition, John Wiley \& Sons, Inc., New York, 1997.

21. Fink L, Seeger W, Ermert L, et al: Real-time quantitative RTPCR after laser assisted cell picking. Nat Med 4: 1329-1334, 1998.

22. Fink L, Kinfe T, Seeger W, Ermert L, Kummer W and Bohle RM: Immunostaining for cell picking and real-time mRNA quantitation. Am J Pathol 157: 1459-1466, 2000.

23. Oku Y, Shimoji T, Takifuji T, et al: Identification of molecular mechanisms for dedifferentiation at the invasion front of colorectal cancer by gene expression analysis. Clin Cancer Res 14: 7215-7222, 2008.

24. Kawai M, Uchiyama K, Tani M, et al: Clinicopathological features of malignant intraductal papillary mucinous tumors of the pancreas. Arch Surg 139: 188-192, 2004. 
25. Zweig MH and Gampell G: Receiver-operating characteristic (ROC) plots: a fundamental evaluation tool in clinical medicine. Clin Chem 39: 561-577, 1993.

26. Förster R, Schubel A, Breitfeld D, et al: CCR7 coordinates the primary immune response by establishing functional microenvironment in secondary lymphoid organs. Cell 99: 23-33, 1999.

27. Saeki H, Moore AM, Brown MJ and Hwang ST: Secondary lymphoid-tissue chemokine (SLC) and CC chemokine receptor 7 (CCR7) participate in the emigration pathway of mature dendritic cells from the skin to regional lymph nodes. J Immunol 162: 2472-2475, 1999.
28. Gunn MD, Tangemann K, Tam C, Cyster JG, Rosen SD and Williams LT: A chemokine expressed in lymphoid high endothelial venules promotes the adhesion and chemotaxis of naive T lymphocytes. Proc Natl Acad Sci USA 95: 258-263, 1998.

29. Shields JD, Emmett MS, Dunn DB, et al: Chemokine-mediated migration of melanoma cells towards lymphatics - a mechanism contributing to metastasis. Oncogene 26: 2997-3005, 2007. 